\title{
pSITE Vectors for Stable Integration or Transient Expression of Autofluorescent Protein Fusions in Plants: Probing Nicotiana benthamiana-Virus Interactions
}

\author{
Romit Chakrabarty, ${ }^{1}$ Rituparna Banerjee, ${ }^{1}$ Sang-Min Chung, ${ }^{2}$ Mark Farman, ${ }^{1}$ Vitaly Citovsky, ${ }^{3}$ \\ Saskia A. Hogenhout, ${ }^{4}$ Tzvi Tzfira, ${ }^{5}$ and Michael Goodin ${ }^{1}$ \\ ${ }^{1}$ Department of Plant Pathology, University of Kentucky, Lexington 40546, U.S.A.; ${ }^{2}$ Department of Life Science, Dongguk \\ University, South Korea; ${ }^{3}$ Department of Biochemistry and Cell Biology, State University of New York, Stony Brook \\ 11794-5215, U.S.A.; ${ }^{4}$ Department of Entomology, The Ohio State University-OARDC, Wooster 44691, U.S.A.; ${ }^{5}$ Department \\ of Molecular, Cellular, \& Developmental Biology, The University of Michigan, Ann Arbor 48109-1048, U.S.A.
}

Submitted 20 December 2006. Accepted 14 February 2007.

\begin{abstract}
Plant functional proteomics research is increasingly dependent upon vectors that facilitate high-throughput gene cloning and expression of fusions to autofluorescent proteins. Here, we describe the pSITE family of plasmids, a new set of Agrobacterium binary vectors, suitable for the stable integration or transient expression of various autofluorescent protein fusions in plant cells. The pSITE vectors permit single-step Gateway-mediated recombination cloning for construction of binary vectors that can be used directly in transient expression studies or for the selection of transgenic plants on media containing kanamycin. These vectors can be used to express native proteins or fusions to monmeric red fluorescent protein or the enhanced green fluorescent protein and its cyan and yellow-shifted spectral variants. We have validated the vectors for use in transient expression assays and for the generation of transgenic plants. Additionally, we have generated markers for fluorescent highlighting of actin filaments, chromatin, endoplasmic reticulum, and nucleoli. Finally, we show that pSITE vectors can be used for targeted gene expression in virusinfected cells, which should facilitate high-throughput characterization of protein dynamics in host-virus interactions.
\end{abstract}

Additional keywords: agroinfiltration, confocal microscopy, nucleolus, SYNV, transformation.

Nicotiana benthamiana Domin (Goodspeed 1954) has emerged as a critically important model host plant for a broad diversity of plant pathogens (Badel et al. 2006; Barajas et al. 2006; Chague et al. 2006; Goodin et al. 2005; Jimenez et al. 2006; Kanneganti et al. 2006; Shung et al. 2006; Sreedharan et al. 2006; Vijaya Palani et al. 2006; Xiao et al. 2003). Additionally, due to its tractability for cell biology and biochemical research, $N$. benthamiana often is used to complement studies initiated with Arabidopsis thaliana, the long-standing paradigm for plant molecular genetics (Deng et al. 2006; Latz et al. 2006; Moeder et al. 2007; Rahier et al. 2006; Zhao et al. 2006), or other plant systems (Wang and Kumar 2006). Moreover, $N$. benthamiana holds a unique position in plant-microbe interac-

Corresponding author: M. Goodin; Telephone: +1 859-257-7445 ext. 80725; Fax: +1 859-323-1961; E-mail: mgoodin@uky.edu tion research because it has become the predominant experimental host for plant viruses, many of which do not infect $A$. thaliana (Christie and Crawford 1978; Coutts and Buck 1985; Quacquarelli 1975). Therefore, research tools and resources to support functional genomics research in $N$. benthamiana are essential to advance our understanding of plant-virus interactions. To this end, microarray-based transcriptional profiling to determine changes in $N$. benthamiana gene expression in response to virus infection have been conducted (Senthil et al. 2005; Whitham et al. 2006). However, integrated plant functional genomics investigations to establish the relationship between changes in the level of host gene expression and the subcellular localization of the encoded proteins in response to pathogen infection requires facile vector systems that permit i) high-throughput construction of recombinant expression vectors, ii) protein expression in either transient assays or transgenic plants without the need for subcloning into different vectors, iii) the ability to efficiently deliver proteins and their interacting targets or substrates to the same cell, iv) expression of proteins in pathogen-infected cells, and v) the ability to monitor membrane or protein dynamics in a large number of cells so as to permit rigorous statistical analyses.

Here, we describe the construction of a novel set of binary vectors that are highly amenable to a wide variety of functional genomics projects in $N$. benthamiana. These "pSITE" vectors, which can be used for stable integration or transient expression of autofluorescent protein (AFP) fusions in plant cells, are derivatives of the exceptional pSAT series described recently (Tzfira et al. 2005), for which modifications are being constructed to suit particular applications in plant biology (Chung et al. 2005; Citovsky et al. 2006). Our rationale for undertaking this project was motivated by the need to eliminate the two-step cloning procedure required to mobilize genes-ofinterest first into pSAT vectors and then into RCS1 or RCS2 binary vectors (Goderis et al. 2002; Tzfira et al. 2005). Therefore, to simplify the pSAT system, we replaced the multiple cloning site in the pSAT-6 AFP cassettes with the destination "DEST" fragment required for Gateway LR-Clonase-mediated recombination cloning (Hartley et al. 2000; Walhout et al. 2000). Briefly, this synthetic construct contains the F plasmidderived $c c d B$ gene, the expression of which is toxic in most lab strains of Escherichia coli. In vitro sequence-specific recombination reactions, directed by flanking "att" sites, result in the 
replacement the $c c d B$ gene with any gene-of-interest (Hartley et al. 2000; Walhout et al. 2000). Subsequent transformation of $E$. coli results in a strong negative selection against $c c d B$-containing plasmids, resulting in highly efficient recovery of recombinant clones. This conversion of the pSAT vectors to be compatible with recombination-based expression systems should promote high-throughput protein localization studies. Ultimately, the pSITE system provides a highly desirable system that can support both transient and stable expression studies without the need for subcloning into different vectors.

Using genes encoded by Sonchus yellow net virus (SYNV), genus Nucleorhabdovirus, and a variety of markers for cellular loci, we validated the pSITE vectors in terms of the five criteria for vectors described above. First, the pSITE vectors have been constructed to permit Gateway-compatible recombination-mediated cloning to produce constructs for the expression of amino( $\mathrm{N}$-series vectors) or carboxy-terminal (C-series vectors) fusions to four different AFPs. Gateway technology, which is amenable to automation and high-throughput expression studies (Gong et al. 2004), has been incorporated into several plant expression systems (Chen et al. 2006; Chung et al. 2005; Curtis and Grossniklaus 2003; Goderis et al. 2002). Moreover, there exists a plethora of Gateway-compatible vectors for protein expression in bacteria, yeast, or insect cells that can be employed to support plant biology research. Second, the pSITE vectors carry a nopaline phosphotransferase (nptII) gene for the selection of transgenic plant tissue on media containing kanamycin. Third, using a synthetic construct composed of a green fluorescent protein (GFP) and red fluorescent protein (RFP) fusion containing a Tobacco vein mottling virus (TVMV) protease cleavage site between the two AFPs, we evaluated the efficiency of targeting a protease and its substrate to the same cell. Fourth, we provide high-resolution micrographs of localization patterns for a variety of proteins expressed transiently in mock-inoculated or SYNVinfected plants. Additionally, we have developed transgenic plants expressing RFP fused to the $N$. benthamiana histone $2 \mathrm{~B}$ (RFP:NbH2B) or Importin- $\alpha 1$ proteins (NbImp- $\alpha 1$ :RFP). Fifth, we demonstrate that infection by SYNV has a statistically significant effect on the localization of nucleolar marker proteins.

Taken together, our data suggest that the pSITE vectors are a significant and much needed addition to the pSAT family of vectors (Chung et al. 2005; Citovsky et al. 2006; Tzfira et al. 2005) and are particularly well suited for dissecting the cell biology of plant-pathogen interactions.

\section{RESULTS}

Twelve pSITE vectors for plant biology research.

We have constructed 12 pSITE vectors for use in a wide variety of research applications (Table 1; Fig. 1). In addition to
AFP-containing plasmids, two derivatives of pSAT-MCS were converted to Gateway compatibility to permit expression of native proteins. These Gateway-adapted cassettes were then mobilized into the pRCS2-ocs-nptII (Chung et al. 2005) (GenBank accession number DQ005456) binary vector containing an nptII gene under the control of octopine synthase promoter and terminator for the selection of transgenic plant material on media containing kanamycin.

Available AFPs in the pSITE vectors include the cyan (CFP), green, and yellow-green (YFP) spectral variants of the GFP, as well as the monomeric RFP. These CFP, GFP, YFP, and RFP genes are found in pSITE vectors $1,2,3$, and 4, respectively (Table 1; Fig. 1). Due to potential problems that can arise when using tetrameric AFPs, (Goodin et al. 2002), we omitted DsRed2 in the pSITE vectors, though it was used in development of the pSAT series (Tzfira et al. 2005). The AFP cassettes in the pSITE vectors are positioned relative to the duplicated $35 \mathrm{~S}$ promoter so as to produce amino-terminal or carboxy-terminal fusions to AFPs. Finally, to ensure translation initiation at the start codon of the gene-of-interest, we removed the NcoI sites in the pSITE-0A and pSITE-NA series vectors because they contained ATG codons in a good translational context.

\section{Validation of the pSITE vectors using proteins encoded by SYNV.}

The pSITE vectors should perform in a fashion identical to that of pSAT derivatives reported earlier (Tzfira et al. 2005). However, we were interested in comparing results obtained with these new vectors with data reported using the pGD vectors, from which expression is controlled by a single $35 \mathrm{~S}$ promoter (Goodin et al. 2002). We were particularly interested in knowing whether the localization patterns of SYNV-encoded proteins were significantly different than previously reported (Goodin et al. 2001, 2002). Therefore, we expressed the SYNV nucleocapsid (N) (Zuidema et al. 1987), matrix (M) (Hillman et al. 1990), and phosphoprotein (P) (Heaton et al. 1987) proteins as fusions to RFP using pSITE-4CA in leaves of mGFP5-endoplasmic reticulum (ER) plants (Fig. 2, A through $\mathrm{X}_{2}$ ). Prior to imaging, the leaves were infiltrated with 4',6-diamidino-2-phenylindole (DAPI)-containing buffer to permit staining of nuclei. In contrast to the results previously reported using DsRed2 (Goodin et al. 2002), RFP-P fusions did not aggregate in the nucleus (Fig. 2, I through P). More importantly, RFP-M fusions localized exclusively to nuclei, whereas the DsRed2 fusion to this protein was highly prone to aggregation (Fig. 2, Q through X) (Goodin et al. 2002). The RFP-N protein, like $M$, was also found only in the nucleus, where it excluded DAPI at its major site of accumulation (Fig. 2, $\mathrm{Y}$ through $\mathrm{X}_{2}$ ). Further, we note that, during the course of

Table 1. pSITE vectors constructed in this study

\begin{tabular}{|c|c|c|c|c|c|c|c|c|c|}
\hline \multirow[b]{2}{*}{ Vector name } & \multicolumn{5}{|c|}{ Fluorescent tag ${ }^{\mathrm{a}}$} & \multicolumn{2}{|c|}{ DEST-terminal } & \multicolumn{2}{|c|}{ NcoI site } \\
\hline & Nil & ECFP & EGFP & EYFP & RFP & $\mathbf{N}$ & $\mathbf{C}$ & Yes & No \\
\hline pSITE-0A & + & $\ldots$ & $\ldots$ & $\ldots$ & $\ldots$ & $\ldots$ & $\ldots$ & + & $\ldots$ \\
\hline pSITE-0B & + & $\ldots$ & $\ldots$ & $\ldots$ & $\ldots$ & $\ldots$ & $\ldots$ & $\ldots$ & + \\
\hline pSITE-1CA & $\ldots$ & + & $\ldots$ & $\ldots$ & $\ldots$ & $\ldots$ & + & + & $\ldots$ \\
\hline pSITE-2CA & $\ldots$ & $\ldots$ & + & $\ldots$ & $\ldots$ & $\ldots$ & + & + & $\ldots$ \\
\hline pSITE-3CA & $\ldots$ & $\ldots$ & $\ldots$ & + & $\ldots$ & $\ldots$ & + & + & $\ldots$ \\
\hline pSITE-4CA & $\ldots$ & $\ldots$ & $\ldots$ & $\ldots$ & + & $\ldots$ & + & + & $\ldots$ \\
\hline pSITE-1NB & $\ldots$ & + & $\ldots$ & $\ldots$ & $\ldots$ & + & $\ldots$ & $\ldots$ & + \\
\hline pSITE-2NA & $\ldots$ & $\ldots$ & + & $\ldots$ & $\ldots$ & + & $\ldots$ & + & $\ldots$ \\
\hline pSITE-2NB & $\ldots$ & $\ldots$ & + & $\ldots$ & $\ldots$ & + & $\ldots$ & $\ldots$ & + \\
\hline pSITE-3NB & $\ldots$ & $\ldots$ & $\ldots$ & + & $\ldots$ & + & $\ldots$ & $\ldots$ & + \\
\hline pSITE-4NA & $\ldots$ & $\ldots$ & $\ldots$ & $\ldots$ & + & + & $\ldots$ & + & $\ldots$ \\
\hline pSITE-4NB & $\ldots$ & $\ldots$ & $\ldots$ & $\ldots$ & + & + & $\ldots$ & $\ldots$ & + \\
\hline
\end{tabular}

${ }^{\mathrm{a}}$ DEST = destination fragment; ECFP , EGFP, EYFP, and RFP = enhanced cyan, green, yellow, and red fluorescent proteins, respectively. 
validating the pSITE vectors, 39 different constructs were generated. Of these, $35(90 \%)$ were detectable by fluorescence microscopy. Of the 10 proteins expressed as amino-terminal fusions (N series vectors), 7 (70\%) were detectable by fluorescence microscopy. In contrast, 28 of 29 (96.5\%) proteins expressed as carboxy-terminal fusions were detectable.

\section{Fluorescent markers for cellular loci.}

Dyes such as DAPI can be infiltrated into leaf tissue to mark particular cellular loci such as the nucleus. In addition, fluorescent proteins with known sites of localization are useful aids in cell biology research (Cutler et al. 2000; Goodin et al. 2002; Panavas et al. 2003; Saint-Jore et al. 2002). Therefore, we are developing RFP- and GFP-tagged markers for all major plant cellular loci in pSITE vectors, and the cognate transgenic $N$. benthamiana plants, in order to provide a standard set of reagents in a common vector background. The first five of these markers and two derivative RFP-tagged lines are shown in Figures 3 and 4.

Using overlap-polymerase chain reaction (PCR), we replaced the GFP in mGFP5-ER (endoplasmic reticulum) with RFP so as to produce a red fluorescent marker for the ER, hereafter referred to as RFP-ER. The A. thaliana basic chitinase signal peptide and Histidine-Aspartate-Glutamate-Leucine (HDEL)-ER retention signal present in mGFP5-ER (Haseloff et al. 1997) are conserved in RFP-ER. Transient expression of this marker in mGFP5-ER plants showed that both proteins accumulated in a similar manner in SYNV-induced intranuclear membranes (Fig. 3B through D) and in the ER (Fig. 3E through G). Fluorescent recovery after photobleaching (FRAP) experiments established that the RFP-ER marker was more sensitive to photobleaching than GFP but otherwise showed statistically identical FRAP kinetics in short-time-course experiments (Fig. 3A)

Fluorescence in transgenic plants expressing RFP fused to the $N$. benthamiana histone $2 \mathrm{~B}$ (RFP:NbH2B) was detected only in the nucleus (Fig. $3 \mathrm{~K}$ through N). Consistent with chromatin targeting, RFP:NbH2B could be used to track all stages of cell division, including anaphase (Fig. 3K through N). RFP: $\mathrm{NbH} 2 \mathrm{~B}$ transgenic plants were phenotypically indistinguishable from wild-type $N$. benthamiana plants, suggesting no adverse effect on these plants due to histone overexpression (data not shown). Likewise, expression of GFP:Talin in $N$. benthamiana resulted in labeling of actin filaments in a manner consistent with published reports (Kost et al. 1998; McCann and Craig 1997). Similar results were obtained with RFP:Talin (data not shown).

In contrast to the predicted results for RFP:ER, GFP:Talin, and RFP:NbH2B, we recovered transgenic plants in which RFP fused to $N$. benthamiana Importin- $\alpha 1$ (NbImp- $\alpha 1: R F P$ ) accumulated preferentially in guard cells (Fig. $3 \mathrm{H}$ ) or in equal levels in all nuclei (Fig. 3I). Mature leaves of the latter plants were curled relative to wild-type plants (Fig. 4A through D), whereas plants with expression only in guard cells were extremely distorted (data not shown).

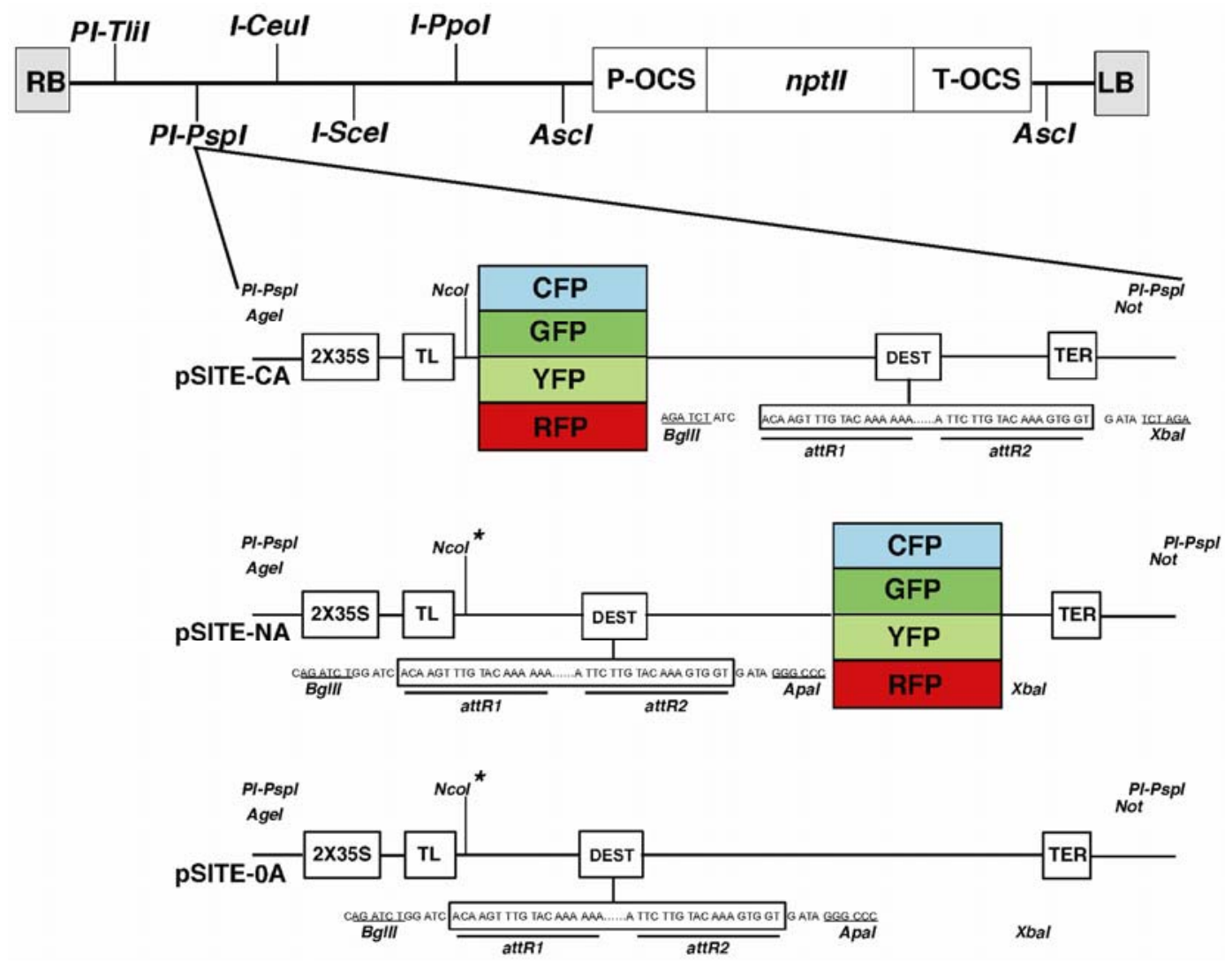

Fig. 1. Schematic representations of pSITE vectors. A, All modified pSAT6 cassettes were cloned into the pRCS2-ocs-nptII binary vector at the PI-Psp1 site. The ability to select transgenic plant cells is conferred by the nptII gene, the expression of which is controlled by the ocs promoter (P-OCS) and terminator (T-OCS). B, "C-series" pSITE vectors for Gateway recombination-mediated construction of binary vectors for expression of proteins-of-interest fused to the carboxy termini of autofluorescent proteins (AFPs). C, "N-series" pSITE vectors for Gateway recombination-mediated construction of binary vectors for expression of proteins-of-interest fused to the amino termini of AFPs. D, "0-series" pSITE vectors for Gateway recombination-mediated construction of binary vectors for expression of native proteins. Protein expression is controlled by a duplicated Cauliflower mosaic virus (CaMV) $35 \mathrm{~S}$ promoter (2X35S) and a Tobacco etch virus translational leader (TL). All vectors employ the CaMV35S transcriptional terminator (TER). NcoI*: this restriction site was deleted to create the pSITE-NB and pSITE-0B vectors. The "DEST" fragment, flanked by LR clonase-mediated recombination sites (attR1 and $a t t R 2)$, contains the $c c d B$ gene derived from the F plasmid. The roles of the $c c d B$ gene and att sites in generating recombinant vectors are defined in the text. 
Immunodetection of AFP fusions expressed from pSITE vectors.

Most protein fusions were easily detectable by Western immunoblotting when transiently expressed in leaf tissues following agroinfiltration (Fig. 5A and B). We could routinely detect fusions up to $97 \mathrm{kDa}$ (RFP:SYNV-G) by simple colorimetric detection without the need for more sensitive detection methods.

In order to assess the efficiency for co-delivery of two fusions into the same cell, we constructed a GFP:RFP fusion that contained a TVMV protease cleavage site between the two AFPs (Figs. 5D, lane 1, and 4E, lane 1). Coexpression with the TVMV protease, either as a native protein (pSITE-0B-TVMVprotease),

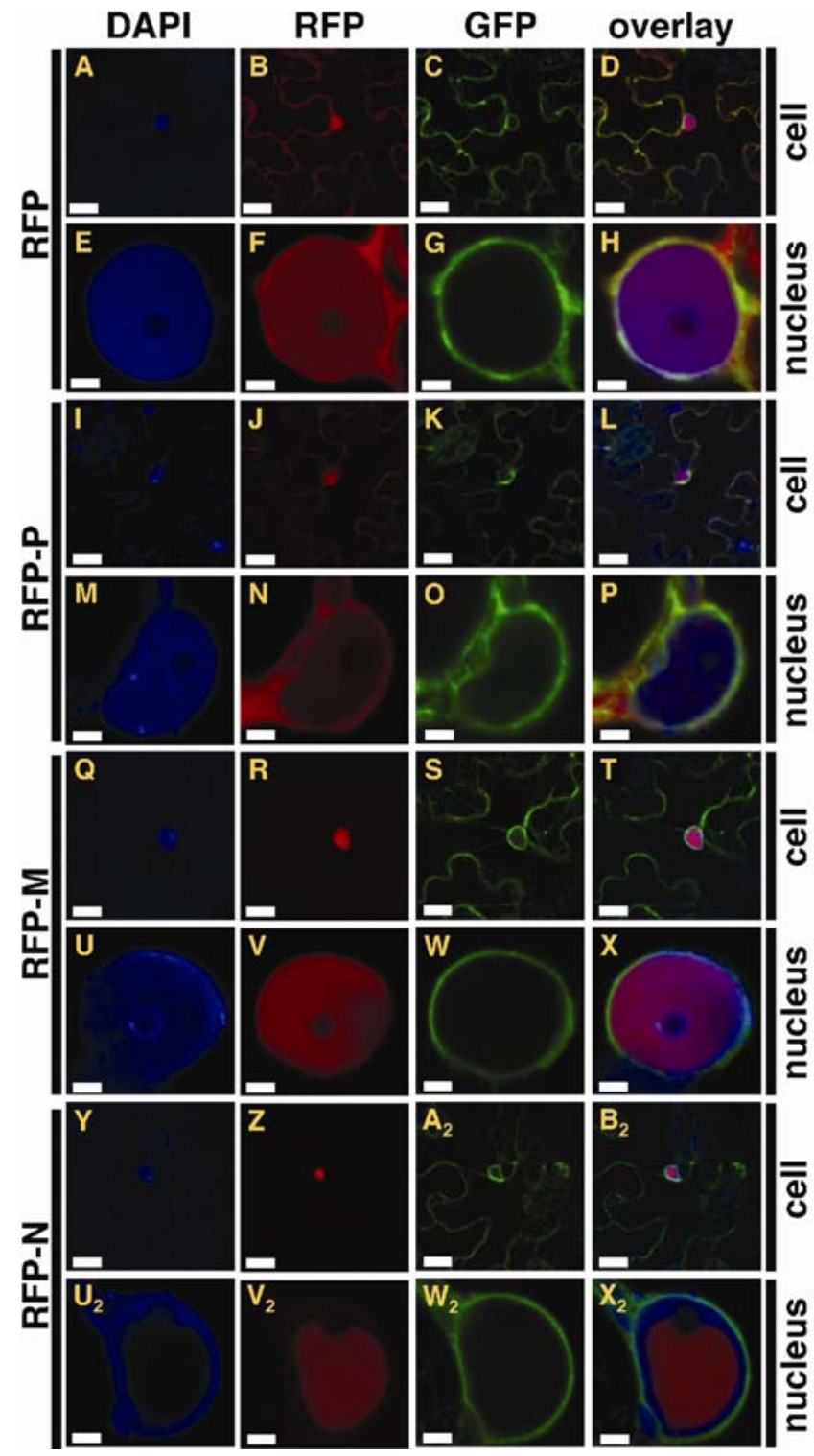

Fig. 2. Confocal micrographs of red fluorescent protein:Sonchus yellow net virus (RFP:SYNV) protein fusions expressed in leaf epidermal cells of mGFP5-endoplasmic reticulum (ER) plants. A through $\mathbf{D}$ and $\mathbf{E}$ through $\mathbf{H}$, Localization pattern of RFP in whole cells and nuclei, respectively. I through $\mathbf{L}$ and $\mathbf{M}$ through $\mathbf{P}$, Localization pattern of RFP-P in whole cells and nuclei, respectively. $\mathbf{Q}$ through $\mathbf{T}$ and $\mathbf{U}$ through $\mathbf{X}$, Localization pattern of RFP-M in whole cells and nuclei, respectively. $\mathbf{Y}$ through $\mathbf{B}_{2}$ and $\mathbf{U}_{2}$ through $\mathbf{X}_{2}$, localization pattern of RFP-N in whole cells and nuclei, respectively. Fluorescence micrographs of the DNA-selective dye (4',6-diamidino-2-phenylindole), RFP, green fluorescent protein (GFP), and the resultant overlay are shown. Scale bars $=10 \mu \mathrm{m}$ (cell) and $2 \mu \mathrm{m}$ (nucleus). These micrographs are representative of data collected after examination of leaf sections taken from a minimum of four independent plants. Due to the ease of transfection, a minimum of 200 cells was examined for each construct.
A
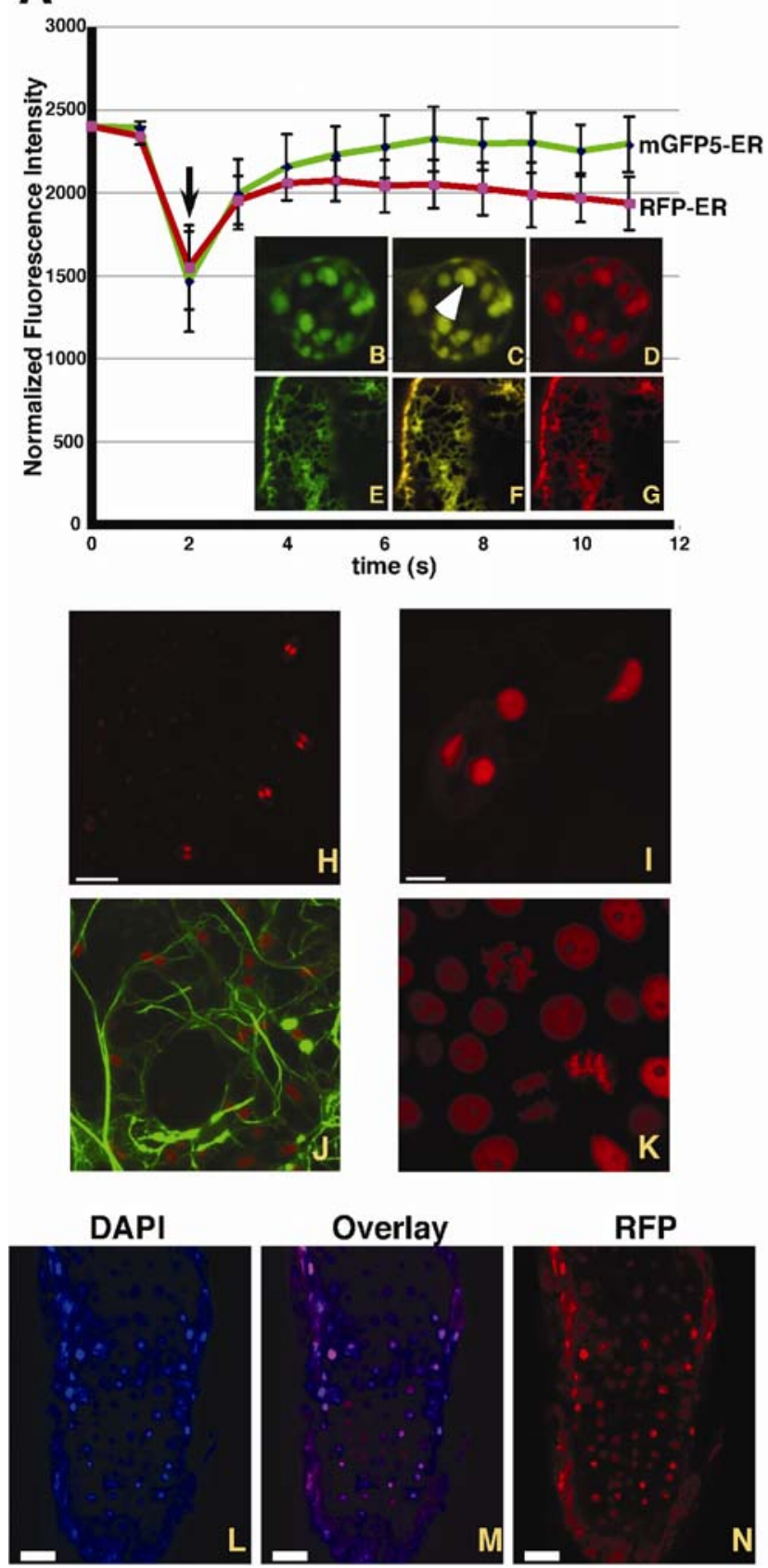

Fig. 3. Confocal micrographs showing localization of fluorescent markers, for a variety of cellular loci, expressed from pSITE vectors. A, Comparative fluorescent recovery after photobleaching (FRAP) kinetics of red fluorescent protein-endoplasmic reticulum (RFP-ER) and mGFP5-ER in Sonchus yellow net virus (SYNV)-induced intranuclear membranes shown in B through D (white arrow). FRAP was monitored following a 50-ms pulse of a 405-nm laser set to full power (black arrow). B through D, Accumulation of RFP-ER and mGFP5-ER in SYNV intranuclear membranes. Confocal micrographs of green fluorescent protein (GFP) (green) and RFP (red) fluorescence, and the corresponding overlay (yellow) are shown. E through G, Transient expression of RFP-ER in mGFP5-ER transgenic plants. Micrographs of GFP, RFP, and their overlay are presented in the same order as in B through D. H, Preferential accumulation of NbImp $\alpha 1:$ RFP in guard cells of a transgenic plant (scale bar $=40 \mu \mathrm{m})$. I, NbImpo1:RFP accumulation in a second line of transgenic plants in which expression levels were equivalent in all nuclei $($ scale bar $=40 \mu \mathrm{m})$. $\mathbf{J}$, Transient expression of GFP:Talin in leaf epidermal cells. Also shown is autofluorescence from chloroplasts (red). K, Nuclear division in root cells of a transgenic plant expressing RFP:NbH2B. $\mathbf{L}$ through $\mathbf{N}$, Root tip of a transgenic plant expressing RFP:NbH2B; scale bar $=40 \mu \mathrm{m}$. L, Roots were counterstained with the DNA-selective dye 4',6-diamidino-2-phenylindole. M, The overlay of panels L and N. N, RFP:NbH2B fluorescence. 
amino-terminal fusion to CFP (pSITE-1NB-TVMVprotease), or carboxy-terminal fusion to CFP (pSITE-1CA-TVMVprotease), resulted in complete digestion of the GFP:RFP reporter. Processing of the reporter occurred even though the TVMVprotease:CFP fusion was not as readily detectable as the amino fusion. Both CFP protein fusions were, however, easily detectable by fluorescence microscopy (data not shown). In general, expression levels were lower when the

same fusion was expressed in the context of transgenic plants compared with levels produced via transient expression (Fig. $5 \mathrm{~F}$ and $\mathrm{G}$ ). This determination was based on data from 10 and 2 independent transgenic lines of RFP:NbH2B and NbImp$\alpha 1:$ RFP, respectively. Interestingly, we were able to recover transgenic plants expressing NbImp- $\alpha 1$ :RFP (expressed from pSITE-4NA) but not RFP:NbImp- $\alpha 2$ (expressed from pSITE4CA), despite the fact that both fusions expressed to high levels in transient assays (data not shown).

\section{Nucleolar dynamics in SYNV-infected cells.}

With the advent of the pSITE and related vectors, highthroughput characterization of the changes in the subcellular lo- calization of host protein in response to virus infection is now possible. Prior to engaging in elucidation of the differential localization of the $N$. benthamiana proteome in mock-inoculated versus virus-infected cells, we conducted pilot studies to map viral proteins in these two cell types (Goodin et al. 2007), as well to determine the effect of SYNV infection on the localization of host proteins (this study). In addition to results to be presented elsewhere, these experiments revealed changes in the localization pattern of RFP:AtFib1 in virus-infected nuclei (Fig. 6). Rather than aberrant localization, we discovered that there was an increase in the percentage of nuclei with multiple nucleoli in SYNV-infected cells (Fig. 6). Briefly, three patterns of nucleolar expression were established. Category 1 included those nuclei in which only one nucleolus could be observed. Category 2 included those nuclei in which accumulation of RFP:AtFib1 could be observed at two loci, which occurred mostly in an "earth and moon" relative size relationship (Fig. 6A through C). This was the predominant category in mock-inoculated cells. Category 3 included those nuclei that contained three or more nucleoli. Patterns of nucleolar distribution were determined in 63 and 69 independent sets of serial optical sections ("z-stacks") of nuclei in
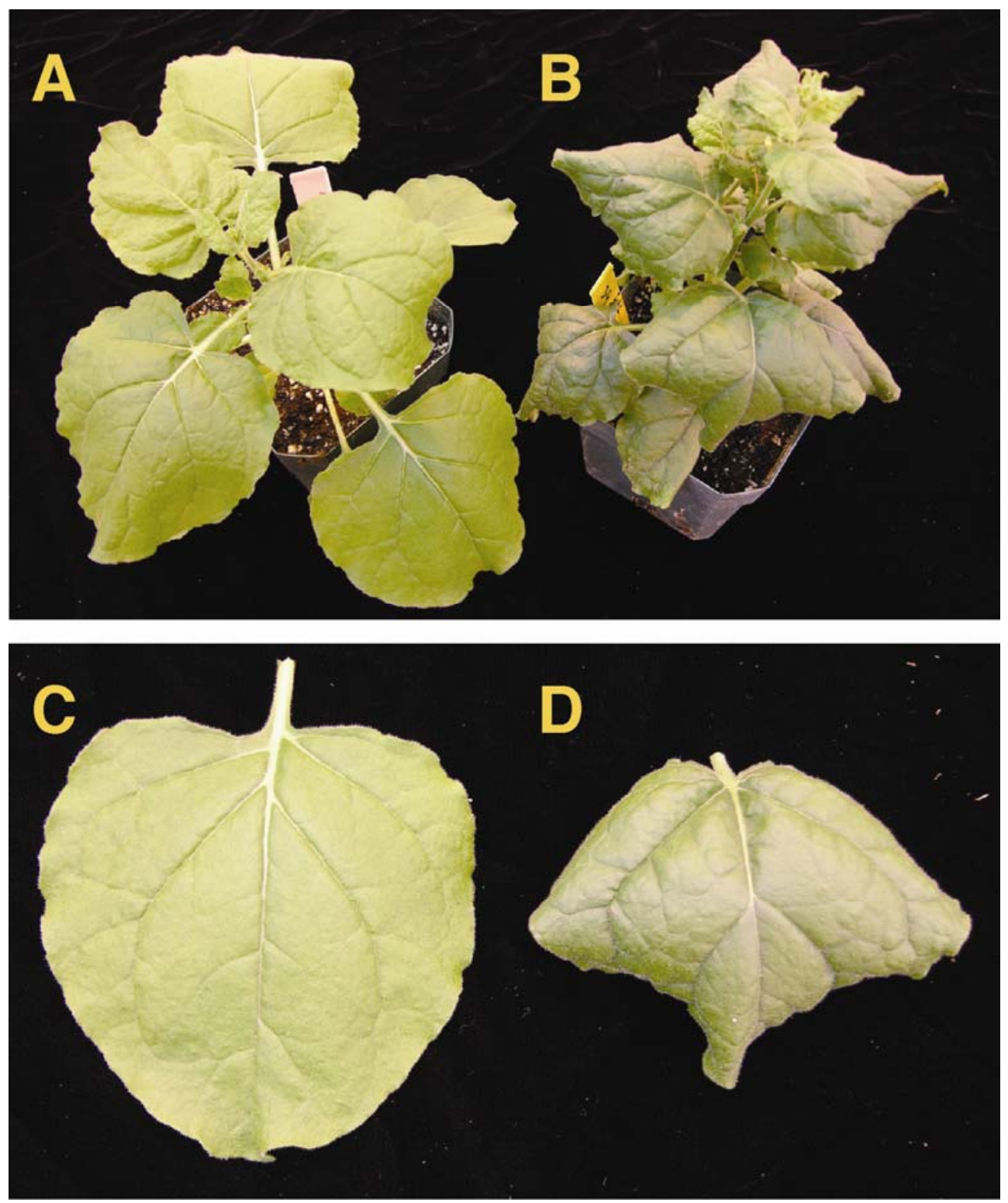

Fig. 4. A, Wild-type Nicotiana benthamiana plant. B, Transgenic $N$. benthamiana plant expressing NbImp- $\alpha 1:$ RFP. C, Fully expanded leaf of $N$. benthamiana plant shown in A. D, Fully expanded leaf of $N$. benthamiana plant shown in B. 
mock-inoculated and virus-infected nuclei (Goodin et al. 2005), respectively. Quantitative analyses of nucleoli in mock-inoculated and virus-infected nuclei revealed that there was an increase in the percentage of nuclei with multiple (more than three) nucleoli per nucleus in virus-infected cells. There was no significant change in the percentage of nucleoli in category 1 (6 and $7 \%$ in mock-inoculated and SYNV-infected nuclei, respectively). Category 2 showed a reduction from 76 to $44 \%$ in mockinoculated and SYNV-infected nuclei, respectively. Finally, category 3 increased from 18 to $49 \%$ in mock-inoculated and SYNV-infected nuclei, respectively. (Fig. 6D through G). A $\chi^{2}$ analysis showed that the differences in localization patterns were statistically significant $(P$ value $=0.01)$. Interestingly, we detected an increase in only the number of large nucleolar bodies, whereas the number of small nucleolar bodies remained at one per nucleolus.

\section{DISCUSSION}

Plant functional genomics research is increasingly dependant upon vector systems that can be used in facile high-throughput protein expression studies. Additionally, N. benthamiana increasingly is being used to dissect the cell biology of hostpathogen interactions and to validate results obtained in $A$. thaliana. Therefore, we have modified the pSAT system to create the pSITE vectors which employ single-step Gateway cloning to produce recombinant binary vectors for the expression of native proteins, or their autofluorescent derivatives, in plant cells (Tzfira et al. 2005). These vectors can be used in transient assays or for the generation of transgenic plants. Unlike other reports of novel binary vectors for plant biology research (Chen et al. 2006; Curtis and Grossniklaus 2003; Earley et al. 2006), we have validated the pSITE vectors in the context of virus-infected cells, thereby demonstrating their suitability for use in probing plant-pathogen interactions. Although this study addressed the changes in the localization of plant proteins in response to virus infection, a parallel study demonstrating the differential localization of SYNV-encoded proteins in virus-infected versus mock-inoculated cells has been reported elsewhere (Goodin et al. 2007).

Fig. 5. Immunodetection of protein fusions expressed from pSITE vectors in agroinfiltrated Nicotiana benthamiana leaves. A, Detection of cyan fluorescent protein (CFP) fusions. Lane1, mock infiltrated leaf; lane 2, empty vector control (pSITE-1CA); lane 3, pSITE-1CA-SYNV-N; lane 4, pSITE-1CA-SYNV-P; lane 5, pSITE-1NB-SYNV-P; lane 6, pSITE-1CASYNV-sc4; lane 7, pSITE-1CA-SYNV-M; lane 8, pSITE-1CA-SYNV-G. B, Detection of red fluorescent protein (RFP) fusions. Lane 1, mock-infiltrated leaf; lane 2, empty vector control (pSITE-4CA); lane 3, pSITE4CA-SYNV-N; lane 4, pSITE-4CA-SYNV-P; lane 5, pSITE-4NA-SYNVP; lane 6, pSITE-4CA-SYNV-sc4; lane 7, pSITE-4CA-SYNV-M; lane 8, pSITE-4CA-SYNV-G. C, Schematic of the fluorescent reporter used to determine the efficiency of co-expression. The green fluorescent protein (GFP):RFP moieties were linked by a Tobacco vein mottling virus (TVMV) protease cleavage site. Detection of D, RFP or $\mathbf{E}$, CFP fusions in agroinfiltrated leaves in which TVMV protease and a fluorescent substrate was co-expressed. Lane1, expression of GFP:RFP (the TVMV protease substrate); lane 2, co-infiltration of GFP:RFP and pSITE-0B-TVMV protease (native TVMV protease); lane 3, co-infiltration GFP:RFP and TVMV protease in pSITE-1NB-TVMV protease (TVMV:CFP protease fusion); lane 4, co-infiltration of GFP:RFP and pSITE-1CA-TVMV protease (CFP:TVMV protease fusion). F, Detection of RFP:NbH2B fusions in transgenic and agroinfiltrated leaf tissue. Lane 1, mock-infiltrated leaf; lane 2, agroinfiltration of pSITE-4CA; lane 3, transgenic leaf tissue expressing RFP:NbH2B from pSITE-4CA; lane 4, agroinfiltrated leaf RFP:NbH2B from pSITE-4CA. G, Immunodetection of importin- $\alpha$; lane 1, mock-infiltrated leaves; lane 2, transgenic plants expressing NbImportin$\alpha 1:$ RFP from $\mathrm{pSITE}-4 \mathrm{NB}$.
The pSITE vectors excelled in their use for standard protein localization studies, as demonstrated with RFP fusions of SYNV-encoded proteins. Several differences of note were observed when comparing these results with similar data obtained with pGD vectors (Goodin et al. 2002). First, using a monomeric form of DsRed proved superior to the use of DsRed2 because previously encountered problems due to tetramerization or aggregation were eliminated. Additionally, we found that a greater amount of SYNV-M and -N accumulated in the nucleus when these proteins were expressed from pSITE vectors. Perhaps this is due to the use of a duplicated $35 \mathrm{~S}$ promoter and translational enhancer in the pSITE vectors compared with a single $35 \mathrm{~S}$ promoter in the pGD vectors. As for the three aforementioned SYNV proteins, RFP-ER, RFP:NbH2B, NbImp- $\alpha 1:$ RFP, and GFP:Talin, all were targeted to their predicted cellular loci. In no case did we observe obvious mislo-
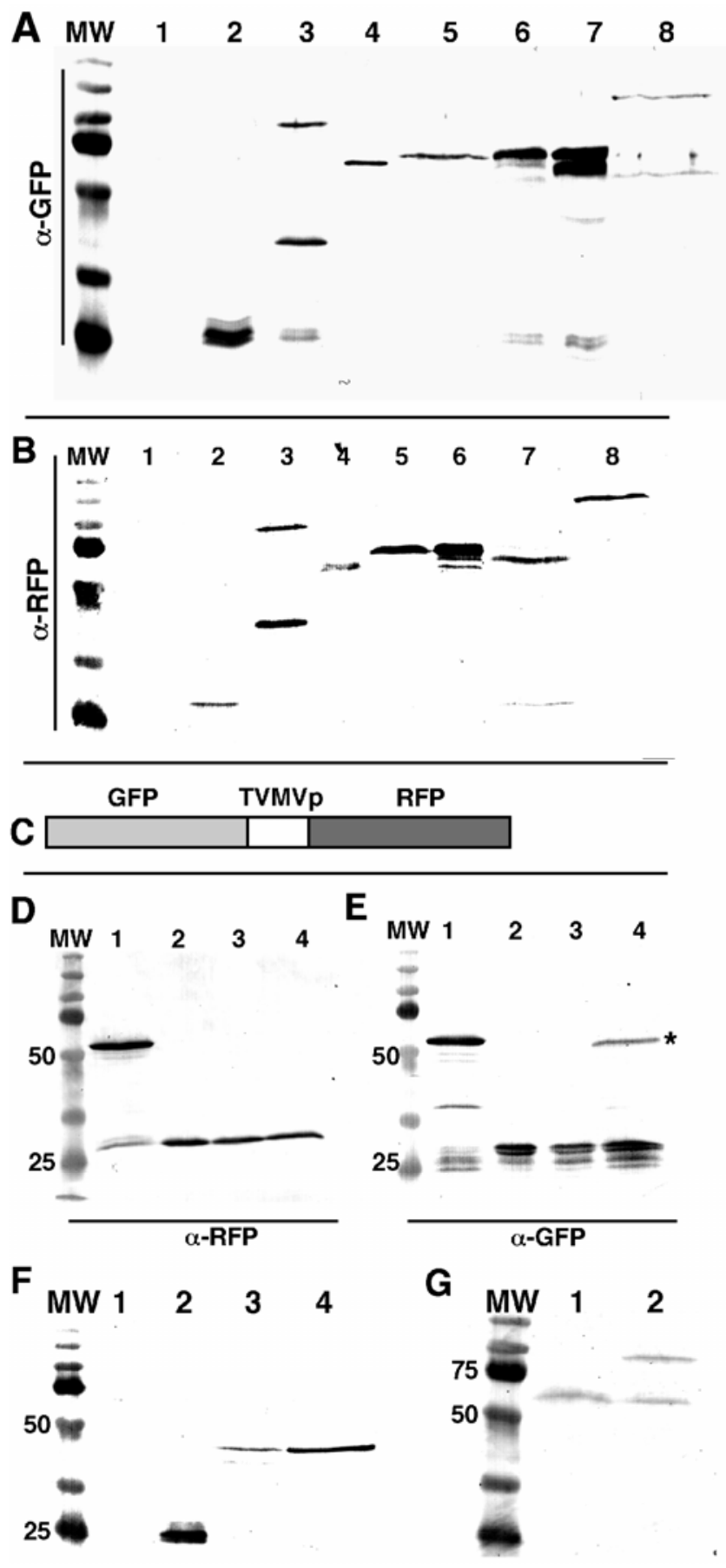
calization of protein fusions. Therefore, we conclude that the pSITE vectors should be extremely useful for general localization studies. Moreover, the compatibility of pSITE vectors with Gateway cloning technology suggests that these vectors should be highly amenable to high-throughput projects ( $\mathrm{Li}$ et al. 2006; Simpson and Pepperkock 2003; Tian et al. 2004; Wiemann et al. 2004). As noted above, $90 \%$ of the constructs made in AFP-containing pSITE vectors yielded protein fusions that were detectable by fluorescence microscopy. Approximately $70 \%$ of amino-terminal fusions ( $\mathrm{N}$-series vectors) were detectable by fluorescence microscopy, whereas $96.5 \%$ of carboxyterminal fusions (C-series vectors) were detected. Despite this apparent greater utility of the $\mathrm{C}$-series vectors, we advise users of these vectors to test expression of genes-of-interest from both the $\mathrm{N}$ - and $\mathrm{C}$-series of vectors. Such tests are simple to
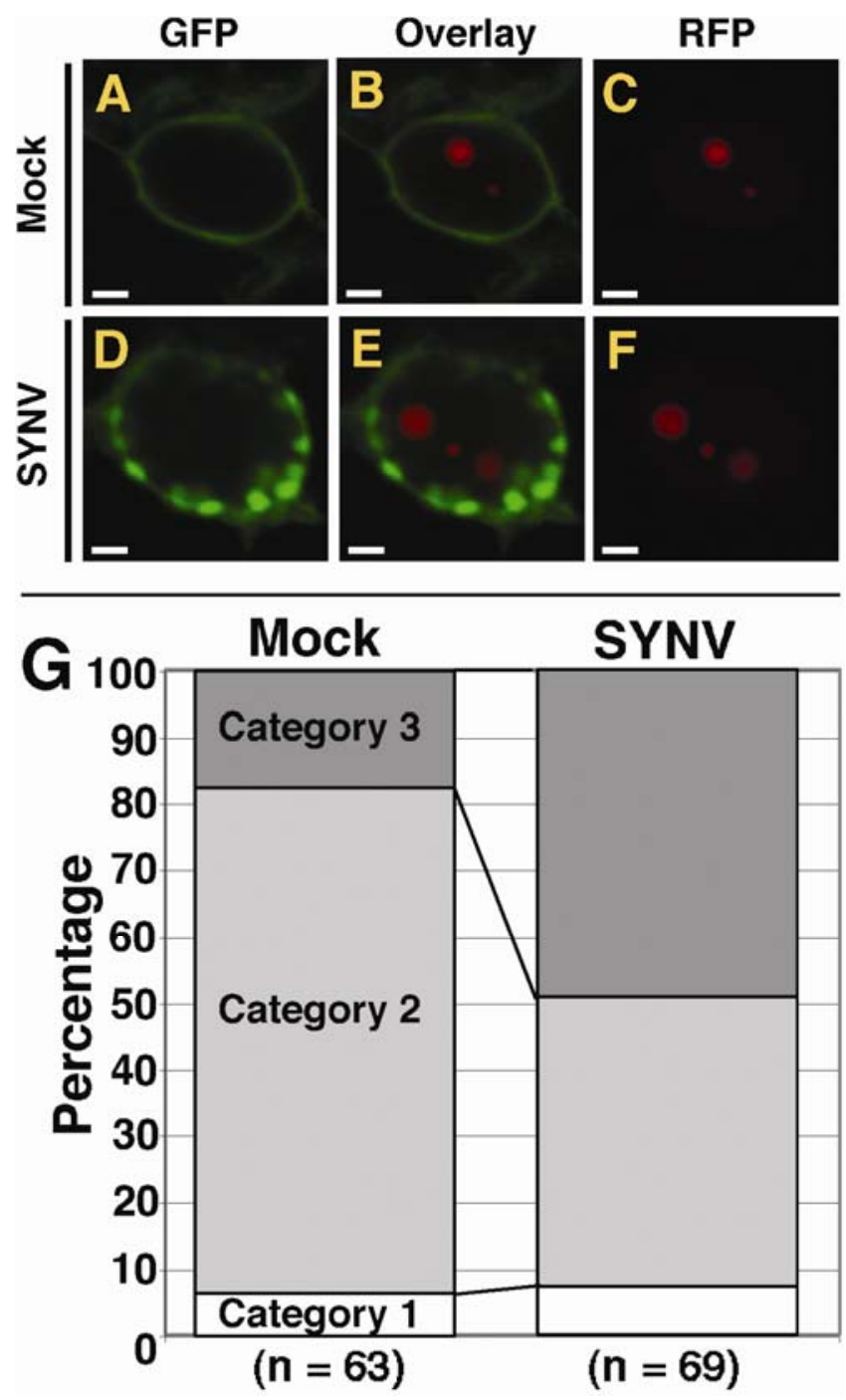

Fig. 6. A through F, Laser scanning confocal micrographs of Nicotiana benthamiana leaf epidermal cells showing shift in the localization of expression patterns of the red fluorescent protein (RFP):AtFib1 nucleolar marker from two loci in $\mathbf{A}$ through $\mathbf{C}$, mock-inoculated cells (mock) to three in D through F, Sonchus yellow net virus (SYNV)-infected cells (SYNV). Transient expression of RFP:AtFib1 was conducted in mGFP5endoplasmic reticulum (ER) plants. G, Quantitative comparison of RFP:AtFib1 expression patterns in mock-inoculated and SYNV-infected cells. Expression patterns were divided into three categories; nuclei with one RFP:AtFib1-marked locus (category 1), nuclei with two RFP:AtFib1marked loci (category 2), and nuclei with three or more RFP:AtFib1marked loci (category 3). A $\chi^{2}$ analysis showed that categories 2 and 3 in mock and SYNV samples were significantly different ( $2 \mathrm{df}, P=0.01)$. conduct, given the presence of stop codons in all three reading frames after the 3 ' lambda phage "att" recombination site in the $\mathrm{C}$-series vectors. Therefore, the same pDONR plasmids, in which genes-of-interest lacking stop codons are cloned, can be used with the $\mathrm{N}$ - and $\mathrm{C}$-series pSITE vectors.

In general, detection of AFP fusions, either in transgenic plants or in transient expression assays, was straightforward. However, stability of the fusions appeared to be highly variable, particularly in the case of the SYNV-N protein; however, this most likely is a consequence of the fusion partner and not the AFPs in the pSITE vectors.

Importantly, our experiments, using the TVMV protease and a fluorescent reporter substrate, strongly indicate that two proteins can be delivered to the same cell with high efficiency. The GFP:RFP reporter was digested to completion, such that the fusion protein was undetectable in co-infiltrated tissue, demonstrating that the TVMV protease was functional whether it was expressed as a native protein or with CFP fused to its carboxy- or amino-terminus. In a more extreme test case, the expression of $\mathrm{NbH} 2 \mathrm{~B}$ (approximately $18 \mathrm{kDa}$ ) as a $35-\mathrm{kDa}$ RFP fusion provided a marker for chromatin dynamics entirely consistent with that expected for a histone marker (BoisnardLorig et al. 2001). Although all proteins or enzymes may not tolerate such additions, these data, along with a wealth of published reports, support the contention that many proteins are functional as AFP fusions.

We note that, for confocal microscopy studies requiring a nuclear marker, the transgenic RFP:NbH2B lines can be imaged using the 543-nm laser line of the common He-Ne lasers. Therefore, this should provide an exceptional alternative to the use of propidium iodide which, being highly cell impermeant, requires incubation of plant tissue in harsh buffers when it is used as a nuclear counterstain (Kumar et al. 2006). Additionally, the use of the cell-permeant DNA-selective dye DAPI requires a UV or near-UV laser which, if unavailable, forces the use of propidium iodide. Thus, the RFP:NbH2B lines may circumvent two major technical limitations that often reduce the quality of micrographs of nuclear localized proteins in plant cells.

Following rigorous technical validation of the pSITE vectors, we employed them to examine the effect of virus infection on the localization of host proteins. These initial experiments revealed a statistically significant increase in the number of nucleoli in SYNV-infected nuclei. Several examples of changes in nucleolar morphology and localization of nucleolar proteins in response to viral infection or interaction with viral proteins have been reported (Hiscox 2007). However, presently it is unclear whether the SYNV-induced increase in nucleolar copy number is a general response to stress or is required for particular aspects of the SYNV life cycle, such as recruitment of ribosomal subunits (Walsh and Mohr 2006), inhibition of specific functions associated with viral proteins (Canto et al. 2006; Uhrig et al. 2004), or other as yet undefined associations. Further experiments utilizing transgenic plants expressing RFP:AtFib1 and a large set of AFP-tagged nucleolar proteins (Pendle et al. 2005) are in progress to provide further insight into the effect of SYNV on nucleolar protein localization and function (data not shown).

In summary, the pSITE vectors described here meet all necessary criteria for support of plant functional genomics projects, namely i) the ability to generate recombinant expression vectors in high-throughput, which we have addressed by constructing Gateway-compatible vectors; ii) the ability to express proteins in either transient assays or in transgenic plants without the need for subcloning into different vectors, which we have demonstrated for a number of proteins; iii) the ability to efficiently deliver proteins and their interacting targets or substrates to the same cell, which we have addressed using TVMV 
protease and a fluorescent substrate; iv) facile expression of protein fusions in mock-inoculated and virus-infected cells, which we have demonstrated using SYNV-encoded proteins as well a number of markers for cellular loci; and v) the ability to monitor membrane or protein dynamics in a large number of cells so as to produce statistically significant results, which we have addressed primarily with FRAP analyses of RFP-ER and the localization of RFP:AtFib1 in mock-inoculated and SYNVinfected leaves.

\section{MATERIALS AND METHODS}

\section{Plant material and growth conditions.}

$N$. benthamiana "16c" plants (referred herein as mGFP5-ER plants) (Brigneti et al. 1998; Haseloff et al. 1997; Ruiz et al. 1998) constitutively express GFP targeted to the ER under the control of the Cauliflower mosaic virus $35 \mathrm{~S}$ promoter. These plants, and the nontransgenic parental line, were grown in a greenhouse under ambient conditions. SYNV inoculations were conducted as described by Goodin and associates (2005).

\section{Construction of the pSITE vectors.}

Gateway-compatible binary vectors for expression of proteins of interest fused to the carboxy- (C-series vectors) or amino-termini (N-series vectors) of AFPs were derived from the pSAT6 vectors (Tzfira et al. 2005). Construction of the $\mathrm{C}$ series vectors first required digestion of pSAT6 vectors containing the enhanced green fluorescent protein (EGFP) gene or its cyan (ECFP) or yellow-shifted (EYFP) spectral variants in pSAT6-DEST-EGFP-C1 (AY818372) and pSAT6-EYFP-C1 (AY818380), and pSAT6-ECFP-C1 (AY818374) and pSAT6RFP-C1 (DQ005474) with BglII and NdeI. The 1,865-bp fragment released from each vector was ligated to a 4,387-bp $B g l$ II and NdeI fragment from pSAT6-DEST-EGFP-C1 to create the intermediate vectors pSAT6-DEST-EYFP-C1 (EF212303), pSAT6-DEST-ECFP-C1 (EF212304), and pSAT6-DEST-RFPC1 (EF212305), respectively. Next, binary vector RCS2 with nptII plant selection marker (DQ005456) and the intermediate vectors pSAT6-DEST-EYFP-C1 (EF212303), pSAT6-DESTECFP-C1 (EF212304), pSAT6-DEST-RFP-C1 (EF212305), and pSAT6-EGFP-C1 (AY818372) were digested with PI-PspI. The $3.5-\mathrm{kb}$ fragments from the intermediate vectors were ligated to the binary vector backbone RCS2 (DQ005456) to make pSITE-3CA (EF212293), pSITE-1CA (EF212302), pSITE-4CA (EF212292), and pSITE-2CA (EF212294).

Similarly, construction of the N-series pSITE vectors required digestion of pSAT6-DEST-EGFP-N1 (AY818370), pSAT6MCS (AY818383), pSAT6A-MCS (EF212312), pSAT6-RFPN1 (DQ005475), pSAT6A-EGFP-N1 (DQ005470), pSAT6AECFP-N1 (DQ005469), and pSAT6A-RFP-N1 (DQ005472) with $B g l \mathrm{II}$ and ApaI. The 1,723-bp fragment released from pSAT6-DEST-EGFP-N1 (AY818370) was ligated to each aforementioned vector, thereby replacing the MCS with the Gateway destination fragment to make pSAT6-DEST (EF212311), pSAT6A-DEST (EF212310), pSAT6-DEST-RFPN1 (EF212309), pSAT6A-DEST-EGFP-N1 (EF212308), pSAT6A-DEST-ECFP-N1 (EF212307), and pSAT6A-DESTRFP-N1 (EF212306) intermediate vectors, respectively. Finally, intermediate vectors were digested with PI-PspI and a $3.5-\mathrm{kb}$ fragment release from each of them; $2.8 \mathrm{~kb}$ from pSAT6DEST (EF212311) and pSAT6A-DEST (EF212310) was ligated to binary vector backbone RCS2 (DQ005456) to make pSITE-0A (EF212300), pSITE-0B (EF212301), pSITE-4NA (EF212293), pSITE-2NA (EF212299), pSITE-2NB (EF212296), pSITE-1NB (EF212297), and pSITE-4NB (EF212298).

The presence of the NcoI site in pSITE-NA vectors results in a 17-amino-acid extension at the amino termini of fusion pro- teins. In order to permit translational initiation from the start codon of proteins-of-interest, the NcoI site in the "A" versions of the pSITE-N and pSITE-0 vectors was removed by sequential digestion with $\mathrm{NcoI}$ and mung bean nuclease followed by ligation with T4DNA ligase (Table 1). Vectors lacking an NcoI site carry the "B" designation (Table 1). Thus, using the same gene-of-interest, protein fusions expressed from a pSITE-NA vector are approximately $2 \mathrm{kDa}$ larger than those expressed from the cognate pSITE-NB vector. Similarly, using the same gene-of-interest, protein fusions expressed from a pSITE-NB vector are approximately $2 \mathrm{kDa}$ smaller than those expressed from the cognate pSITE-CA vector, because the NcoI site is retained in these latter vectors (Fig. 1).

\section{Gateway cloning of genes into pSITE vectors.}

A two-step procedure was used to incorporate recombination att sites into PCR products in order to make them suitable for use as substrates for Gateway BP clonase-mediated (Invitrogen Corp, Carlsbad, CA, U.S.A.) recombination into pDONR 221 (Invitrogen). Briefly, genes-of-interest were amplified using gene-specific forward and reverse primers that each contained $5^{\prime}$ extensions corresponding to half of the att site. The PCR products were then reamplified using "universal" primers that incorporated the remainder of the att sites. PCR amplification was conducted with Phusion High Fidelity DNA Polymerase (Finnzymes, Espoo, Finland) according to manufacturer's recommendations in a Bio-Rad (Hercules, CA, U.S.A.) thermal cycler.

The PCR products containing complete att sites were purified and then cloned into pDONR221 vector by overnight incubation in the presence of Gateway BP clonase, per the manufacturer's recommendation, at $25^{\circ} \mathrm{C}$. In this manner, "entry clones" for SYNV-N (L32603), SYNV-P (AY971951), SYNVsc4 (L32604) SYNV-M (M35689) SYNV-G(L32603) N. benthamiana histone 2B (EF189156), $N$. benthamiana Importin- $\alpha$ homologues 1 and 2 (EF137253 and EF137254) (Kanneganti et al. 2007), A. thaliana Fibrillarin 1(AtFib1 and NM_124626.3) Barneche et al. 2000), TVMV protease (NC_001768), and RFP with N-terminal fusion of TVMV protease cleavage site were created. Next, the plasmid DNA from the positive entry clones was introduced into a pSITE vector of choice by overnight incubation of Gateway LR clonase recombination reaction (as per the manufacturer's recommendation) at $25^{\circ} \mathrm{C}$. Finally, each recombinant pSITE vector was transformed into Agrobacterium tumefaciens LBA4404.

\section{Transient expression of proteins in leaf epidermal cells.}

Suspensions of $A$. tumefaciens were infiltrated into leaves of N. benthamiana as previously described (Goodin et al. 2002; Tsai et al. 2005). In order to express proteins in SYNVinfected cells, symptomatic leaves of plants were infiltrated at the peak of symptom expression, typically 10 to 14 days post inoculation. Following a 48-h incubation of infiltrated plants under constant illumination at $25^{\circ} \mathrm{C}$, water-mounted sections of leaf tissue were examined by confocal microscopy.

\section{Laser scanning confocal microscopy.}

All confocal microscopy was performed on an Olympus FV1000 (Olympus America Inc., Melville, NY, U.S.A.). DAPI, CFP, GFP, YFP, and RFP were excited using 405-, 440-, 488-, 515-, and 543-nm laser lines, respectively. When using multiple fluors simultaneously, images were acquired sequentially line-by-line in order to eliminate excitation and emission cross talk. The primary objective used to produce the micrographs in this study was an Olympus water immersion PLAPO60XWLSM (NA 1.0). Image acquisition was conducted at a resolution of 512-by-512 pixels and a scan rate of 10 
$\mu \mathrm{s} /$ pixel. Control of the microscope, as well as image acquisition and exportation as TIFF files, was controlled by Olympus Fluoview software version 1.5. Image analysis was conducted using Photoshop 7.0 (Adobe Systems Incorporated, San Jose, CA, U.S.A.) and Canvas 8.0 (Deneba Software, Miami).

\section{FRAP.}

FRAP experiments were conducted using leaf tissue harvested 10 to 14 days post inoculation from SYNV-infected mGFP5ER plants. Mock-inoculated plants of similar age were used as controls. FRAP experiments were performed using the Olympus FV1000 described above. Briefly, 25- $\mathrm{mm}^{2}$ sections of leaf tissue were mounted on glass slides in water and covered with a glass coverslip. Imaging for FRAP experiments was conducted using a $\times 60$ objective and 488-nm laser line from a multiline argon laser set at $0.3 \%$ power. Regions of interest (ROIs) were photobleached for $50 \mathrm{~ms}$ using a 405-nm diode laser, set at full power, which was delivered via the FV1000 Simultaneous scanner. Images for FRAP analyses were acquired at a resolution of 512-by-512 pixels and a scan-rate of $2 \mu \mathrm{s} /$ pixel, which was necessary to monitor fast protein dynamics. Two images were acquired prior to photobleaching followed by an additional seven images to monitor fluorescence recovery. Quantitative fluorescence data, in Excel format, and confocal images, in TIFF format, were exported using Olympus Fluoview software. FRAP experiments were repeated three times for each ROI, with 2 min between bleaching events in order to allow full recovery of fluorescence. Replicated fluorescence intensity data were averaged and these data were normalized across experiments. Mean and standard deviations for fluorescence intensity at each time point were calculated and plotted using Excel software (Microsoft Corporation, Redmond, WA, U.S.A.).

\section{A. tumefaciens-mediated plant transformation.}

Due to its widespread familiarity in the plant biology community, all transgenic plants developed in this study were derived from the parental line used to generate the "16c" line of $N$. benthamiana mGFP5-ER plants (Brigneti et al. 1998, Haseloff et al. 1997; Ruiz et al. 1998). The genetic variation among $N$. benthamiana accessions in use is poorly defined at present. Therefore, we have standardized all of our $N$. benthamiana resources by working exclusively with the $16 \mathrm{c}$ parent. The transformation procedure employed was an adaptation of the methods described by Horsch and associates (1985) and Kalantidis and associates (2002). Briefly, A. tumefaciens LBA4404 carrying the pSITE-4CA- $N$. benthamiana histone 2B (RFP:NbH2B) or pSITE-4NB- $N$. benthamiana Importin$\alpha 1$ (NbImp- $\alpha 1:$ RFP) binary vectors were grown overnight at $28^{\circ} \mathrm{C}$. Surface-sterilized leaves from greenhouse-grown $N$. benthamiana plants were infected with the Agrobacterium culture. The explants were co-cultivated for 2 days on Murashige and Skoog (1962) media (MS) supplemented with benzylaminopurine and indole-3-acetic acid at 2 and $0.5 \mathrm{mg} / \mathrm{liter}$, respectively. Putative transgenic shoots from the leaf explants were induced on the same medium supplemented with cefotaxime (500 mg/liter) and kanamycin (150 mg/liter). Regenerated shoots were transferred to rooting media that included MS with cefotaxime (250 mg/liter) and kanamycin (50 mg/liter). After rooting, the plants were transferred to soil in pots and were kept in culture room at $25^{\circ} \mathrm{C}$ with a 16 -h photoperiod. Later, seed were collected from selfed $\mathrm{T}_{0}$ plants.

\section{Western immunoblotting.}

Leaf disc samples were collected in triplicate from infiltrated or transgenic $N$. benthamiana leaves using a $1-\mathrm{cm}$ cork borer. The tissue samples were ground in $200 \mu \mathrm{l}$ of $2 \times$ sodium dodecyl sulfate polyacrylamide gel electrophoresis (SDS-
PAGE) loading buffer $(0.5 \mathrm{M}$ Tris-HCl, $20 \%$ glycerol [vol/vol], 2\% SDS [wt/vol], 1.4 M $\beta$-mercaptoethanol, $0.001 \%$ bromophenol blue [wt/vol], $\mathrm{pH}$ 6.8). Following electrophoretic separation on $12 \%$ SDS-PAGE gels, proteins were transferred onto nitrocellulose membranes, which were incubated in buffers containing polyclonal antibodies to DsRed (1:2000 dilution; Clontech, Mountain View, CA, U.S.A.) or GFP (1:2000 dilution; Aves Labs, Tigard, OR, U.S.A.), as appropriate. Detection of $N$. benthamiana importin- $\alpha$ was performed using polyclonal antibodies raised against the recombinant $A$. thaliana importin- $\alpha$ (1:3000 dilution; Rose Biotechnology, Palo Alto, CA, U.S.A.). After incubation in secondary antibodies (1:20,000 dilution; Sigma, St. Louis) conjugated to alkaline phosphatase, the immunoblots were developed in sodium bicarbonate buffer containing the chromogenic substrate 5-bromo-4-chloro-3indolyl phosphate and oxidant nitro blue tetrazolium chloride. We note that detection of AFP fusions was highly dependent upon the cloned "gene-of-interest." For example, RFP:SYNV$\mathrm{G}$ expression levels always were lower than RFP alone or RFP:SYNV-P. Therefore, the loading of protein samples corresponding to each construct was titrated to determine the optimal volume to produce immunoblots with clearly identifiable bands. Composite immunoblots then were produced to show that fusions of the predicted size were produced in planta. Due to an emphasis on characterizing protein localization, expression levels for each construct relative to the total amount of protein in extracts from infiltrated leaves was not determined.

\section{Statistical analyses.}

A quantitative analysis of the localization of RFP:AtFib1, a nucleolar marker protein, in virus-infected and mock-inoculated cells was conducted using $\chi^{2}$ analysis $(P=0.01 ; 2$ degrees of freedom) (Steel and Torrie 1980).

\section{ACKNOWLEDGMENTS}

We wish to thank D. Baulcombe for the gift of seed of the N. benthamiana accession from which the $16 \mathrm{c}$ line was derived. We also thank $\mathrm{R}$. McCann for providing the cDNA clone of Talin. This research was supported by the United States Department of Agriculture (USDA) and Kentucky Tobacco Research and Development Center awards to M. Goodin; a Kentucky Science and Engineering Foundation award to M. Farman and M. Goodin; University of Michigan start-up funds to T. Tzfira and grants from the National Science Foundation, National Institutes of Health, USDA, Binational Agricultural and Research Development, and Binational Science Foundation to V. Citovsky; and National Research Initiative-USDA-Cooperative State Research Education and Extension Service and Ohio Agriculture Research and Development Center research enhancement and competitive grants awarded to S. Hogenhout. Finally, we thank A. Crume for exceptional greenhouse management and maintenance of the $N$. benthamiana plants as well as $\mathrm{S}$. Yelton for critical reading of the manuscript. This manuscript is published with the approval of the Director of the Kentucky Agricultural Experiment Station as Journal Article \#07-12-018.

\section{LITERATURE CITED}

Badel, J. L., Shimizu, R., Oh, H. S., and Collmer A. 2006. A Pseudomonas syringae pv. tomato avrE1/hopM1 mutant is severely reduced in growth and lesion formation in tomato. Mol. Plant-Microbe Interact. 19:99-111.

Barajas, D., Tenllado, F., and Diaz-Ruiz, J. R. 2006. Characterization of the recombinant forms arising from a Potato virus $X$ chimeric virus infection under RNA silencing pressure. Mol. Plant-Microbe Interact. 19:904-913.

Barneche, F., Steinmetz, F., and Echeverria, M. 2000. Fibrillarin genes encode both a conserved nucleolar protein and a novel small nucleolar RNA involved in ribosomal RNA methylation in Arabidopsis thaliana. J. Biol. Chem. 275:27212-2720.

Boisnard-Lorig, C., Colon-Carmona, A., Bauch, M., Hodge, S., Doerner, P., Bancharel, E., Dumas, C., Haseloff, J., and Berger F. 2001. Dynamic analyses of the expression of the HISTONE::YFP fusion protein in Arabidopsis show that syncytial endosperm is divided in mitotic domains. Plant Cell. 13:495-509. 
Brigneti, G., Voinnet, O., Li, W. X., Ji, L. H., Ding, S.-W., and Baulcombe, D. C. 1998. Viral pathogenicity determinants are suppressors of transgene silencing in Nicotiana benthamiana. EMBO (Eur. Mol. Biol. Organ.) J. 17:6739-6746.

Canto, T., Uhrig, J. F., Swanson, M., Wright, K. M., and MacFarlane, S. A 2006. Translocation of Tomato bushy stunt virus P19 protein into the nucleus by ALY proteins compromises its silencing suppressor activity. J. Virol. 80:9064-9072.

Chague, V., Danit, L. V., Siewers, V., Schulze-Gronover, C., Tudzynski, P., Tudzynski, B., and Sharon, A. 2006. Ethylene sensing and gene activation in Botrytis cinerea: A missing link in ethylene regulation of fungusplant interactions? Mol. Plant-Microbe Interact. 19:33-42.

Chen, Q. J., Zhou, H.M., Chen, J., and Wang, X. C. 2006. A Gatewaybased platform for multigene plant transformation. Plant Mol. Biol. 62:927-936.

Christie, S. R., and Crawford, W. E. 1978. Plant virus range of Nicotiana benthamiana. Plant Dis. Rep. 62:20-22.

Chung, S. M., Frankman, E. L., and Tzfira, T. 2005. A versatile vector system for multiple gene expression in plants. Trends Plant Sci. 10:357361.

Citovsky, V., Lee, L. Y., Vyas, S., Glick, E., Chen, M.H., Vainstein, A., Gafni, Y., Gelvin, S. B., and Tzfira, T. 2006. Subcellular localization of interacting proteins by bimolecular fluorescence complementation in planta. J. Mol. Biol. 362:1120-1131.

Coutts, R. H., and Buck, K. W. 1985. DNA and RNA polymerase activities of nuclei and hypotonic extracts of nuclei isolated from tomato golden mosaic virus infected tobacco leaves. Nucleic Acids Res. 13:78817897.

Curtis, M. D., and Grossniklaus, U. 2003. A Gateway cloning vector set for high-throughput functional analysis of genes in planta. Plant Physiol. 133:462-469.

Cutler, S. R., Ehrhardt, D. W., Griffitts, J. S., and Somerville, C. R. 2000. Random GFP::cDNA fusions enable visualization of subcellular structures in cells of Arabidopsis at a high frequency. Proc. Natl. Acad. Sci. U.S.A. 97:3718-3723

Deng, W., Luo, K., Li, D., Zheng, X., Wei, X., Smith, W., Thammina, C., Lu, L., Li, Y., and Pei, Y. 2006. Overexpression of an Arabidopsis magnesium transport gene, AtMGT1, in Nicotiana benthamiana confers Al tolerance. J. Exp. Bot. 57:4235-4243

Earley, K. W., Haag, J. R., Pontes, O., Opper, K., Juehne, T., Song, K., and Pikaard, C. S. 2006. Gateway-compatible vectors for plant functional genomics and proteomics. Plant J. 45:616-629.

Goderis, I. J., De Bolle, M. F., Francois, I. E., Wouters, P. F., Broekaert, W. F., and Cammue, B. P. 2002. A set of modular plant transformation vectors allowing flexible insertion of up to six expression units. Plant Mol. Biol. 50:17-27.

Gong, W., Shen, Y. P., Ma, L. G., Pan, Y., Du, Y. L., Wang, D. H., Yang, J. Y., Hu, L. D., Liu, X. F., Dong, C. X., Ma, L., Chen, Y. H., Yang, X. Y., Gao, Y., Zhu, D., Tan, X., Mu, J. Y., Zhang, D. B., Liu, Y. L., DineshKumar, S. P., Li, Y., Wang, X. P., Gu, H. Y., Qu, L. J., Bai, S. N., Lu, Y. T., Li, J. Y., Zhao, J. D., Zuo, J., Huang, H., Deng, X. W., and Zhu, Y. X. 2004. Genome-wide ORFeome cloning and analysis of Arabidopsis transcription factor genes. Plant Physiol. 135:773-782.

Goodin, M. M., Austin, J., Tobias, R., Fujita, M., Morales, C., and Jackson, A. O. 2001. Interactions and nuclear import of the $\mathrm{N}$ and $\mathrm{P}$ proteins of sonchus yellow net virus, a plant nucleorhabdovirus. J. Virol. 75:9393406

Goodin, M. M., Dietzgen, R. G., Schichnes, D., Ruzin, S., and Jackson, A. O. 2002. pGD vectors: Versatile tools for the expression of green and red fluorescent protein fusions in agroinfiltrated plant leaves. Plant $\mathbf{J}$. 31:375-383

Goodin, M., Yelton, S., Ghosh, D., Mathews, S., and Lesnaw, J. 2005. Live-cell imaging of rhabdovirus-induced morphological changes in plant nuclear membranes. Mol. Plant-Microbe Interact. 18:703-709.

Goodin, M., Chakrabarty, R., Yelton, S., Martin, K., Clark, A., and Brooks, R. 2007. Membrane and protein dynamics in live plant nuclei infected with Sonchus yellow net virus, a plant-adapted rhabdovirus. J. Gen. Virol. 88:1810-1820.

Goodspeed, T. H. 1954. The Genus Nicotiana: Origins, Relationships and Evolution of Its Species in the Light of their Distribution, Morphology and Cytogenetics. Chronica Botanica, Waltham, MA, U.S.A.

Hartley, J. L., Temple, G. F., and Brasch, M. A. 2000. DNA cloning using in vitro site-specific recombination Genome Res. 10:1788-1795.

Haseloff, J., Siemering, K. R., Prasher, D. C., and Hodge, S. 1997. Removal of a cryptic intron and subcellular localization of green fluorescent protein are required to mark transgenic Arabidopsis plants brightly. Proc. Natl. Acad. Sci. U.S.A. 94:2122-2127.

Heaton, L. A., Zuidema, D., and Jackson, A. O. 1987. Structure of the M2 protein gene of sonchus yellow net virus. Virology 161:234-241.

Hillman, B. I., Heaton, L. A., Hunter, B. G., Modrell, B., and Jackson, A.
O. 1990. Structure of the gene encoding the M1 protein of Sonchus yellow net virus. Virology 179:201-207.

Hiscox, J. A. 2007. RNA viruses: Hijacking the dynamic nucleolus. Nat. Rev. Microbiol. 5:119-127.

Horsch, R. B., Fry, J. E., Hoffmann, N. L., Eichholtz, D., Rogers, S. G., and Fraley, R. T. 1985. A simple and general method for transferring genes into plants. Science 227:1229-1231.

Jimenez, I., Lopez, L., Alamillo, J. M., Valli, A., and Garcia, J.A. 2006. Identification of a Plum pox virus CI-interacting protein from chloroplast that has a negative effect in virus infection. Mol. Plant-Microbe Interact. 19:350-358

Kalantidis, K., Psaradakis, S., Tabler, M., and Tsagris, M. 2002. The occurrence of CMV-specific short Rnas in transgenic tobacco expressing virus-derived double-stranded RNA is indicative of resistance to the virus. Mol. Plant-Microbe Interact. 15:826-33.

Kanneganti, T. D., Huitema, E., Cakir, C., and Kamoun, S. 2006. Synergistic interactions of the plant cell death pathways induced by Phytophthora infestans Nepl-like protein PiNPP1.1 and INF1 elicitin. Mol. Plant-Microbe Interact. 19:854-863.

Kanneganti, T.-D., Bai, X., Tsai, C.-W., Win, J., Meulia, T., Goodin, M., Kamoun, S., and Hogenhout, S. 2007. A functional genetic assay for nuclear trafficking in plants. Plant J. 50:149-158.

Kost, B., Spielhofer, P., and Chua, N. H. 1998. A GFP-mouse talin fusion protein labels plant actin filaments in vivo and visualizes the actin cytoskeleton in growing pollen tubes. Plant J. 16:393-401.

Kumar, P. P., Usha, R., Zrachya, A., Levy, Y., Spanov, H., and Gafni Y. 2006. Protein-protein interactions and nuclear trafficking of coat protein and betaC1 protein associated with Bhendi yellow vein mosaic disease. Virus Res. 122:127-136.

Latz, A., Ivashikina, N., Fischer, S., Ache, P., Sano, T., Becker, D., Deeken, R., and Hedrich, R. 2007. In planta AKT2 subunits constitute a pH- and $\mathrm{Ca}(2+)$-sensitive inward rectifying $\mathrm{K}(+)$ channel. Planta. 225:1179-1191.

Li, S., Ehrhardt, D.W., and Rhee, S. Y. 2006. Systematic analysis of Arabidopsis organelles and a protein localization database for facilitating fluorescent tagging of full-length Arabidopsis proteins. Plant Physiol. 141:527-539.

McCann, R. O., and Craig, S. W. 1997. The I/LWEQ module: A conserved sequence that signifies F-actin binding in functionally diverse proteins from yeast to mammals. Proc. Natl. Acad. Sci. U.S.A. 94:5679-5684.

Moeder, W., Del Pozo, O., Navarre, D. A., Martin, G. B., and Klessig, D. F. 2007. Aconitase plays a role in regulating resistance to oxidative stress and cell death in Arabidopsis and Nicotiana benthamiana. Plant Mol. Biol. 63:273-287.

Murashige, T., and Skoog, F. 1962. A revised medium for rapid growth and bioassays with tobacco tissue cultures. Physiol. Plant. 15:473-97.

Panavas, T., Hawkins, C. M., Panaviene, Z., and Nagy, P. D. 2003. The role of the p33:p33/p92 interaction domain in RNA replication and intracellular localization of $\mathrm{p} 33$ and $\mathrm{p} 92$ proteins of Cucumber necrosis tombusvirus. Virology 338:81-95.

Pendle, A. F., Clark, G. P., Boon, R., Lewandowska, D., Lam, Y. W. Andersen, J., Mann, M., Lamond, A., Brown, J. W., and Shaw, P. J. 2005. Proteomic analysis of the Arabidopsis nucleolus suggests novel nucleolar functions. Mol. Biol. Cell. 16:260-269.

Quacquarelli, A. 1975. Nicotiana benthamiana Domin, as a host for plant viruses. Phytopathol. Mediterr. 14:36-39.

Rahier, A., Darnet, S., Bouvier, F., Camara, B., and Bard, M. 2006. Molecular and enzymatic characterizations of novel bifunctional 3betahydroxysteroid dehydrogenases/C-4 decarboxylases from Arabidopsis thaliana. J. Biol. Chem. 281:27264-27277.

Ruiz, M. T., Voinnet, O., and Baulcombe, D. C. 1998. Initiation and maintenance of virus-induced gene silencing. Plant Cell. 10:937-946.

Saint-Jore, C. M., Evins, J., Batoko, H., Brandizzi, F., Moore, I., and Hawes, C. 2002. Redistribution of membrane proteins between the Golgi apparatus and endoplasmic reticulum in plants is reversible and not dependent on cytoskeletal networks. Plant J. 29:661-678.

Senthil, G., Liu, H., Puram, V. G., Clark, A., Stromberg, A., and Goodin, M. M. 2005. Specific and common changes in Nicotiana benthamiana gene expression in response to infection by enveloped viruses. J. Gen. Virol. 86:2615-2625

Shung, C. Y., Sunter, J., Sirasanagandla, S. S., and Sunter, G. 2006. Distinct viral sequence elements are necessary for expression of Tomato golden mosaic virus complementary sense transcripts that direct AL2 and AL3 gene expression. Mol. Plant-Microbe Interact. 19:1394-1405.

Simpson, J. C., and Pepperkok, R. 2003. Localizing the proteome. Genome Biol. 4:240.

Sreedharan, A., Penaloza-Vazquez, A., Kunkel, B. N., and Bender, C. L. 2006. CorR regulates multiple components of virulence in Pseudomonas syringae pv. tomato DC3000. Mol. Plant-Microbe Interact. 19:768-779.

Steel, R. G. D., and Torre, J. H. 1980. Principles and Procedures of Statistics, 2nd ed. McGraw-Hill, New York. 
Tian, G. W., Mohanty, A., Chary, S. N., Li, S., Paap, B., Drakakaki, G. Kopec, C. D., Li, J., Ehrhardt, D., Jackson, D., Rhee, S. Y., Raikhel, N. V., and Citovsky, V. 2004. High-throughput fluorescent tagging of fulllength Arabidopsis gene products in planta. Plant Physiol. 135:25-38.

Tsai, C. W., Redinbaugh, M. G., Willie, K. J., Reed, S., Goodin, M., and Hogenhout, S. A. 2005. Complete genome sequence and in planta subcellular localization of maize fine streak virus proteins. J. Virol. 79:5304-5314.

Tzfira, T., Tian, G. W., Lacroix, B., Vyas, S., Li, J., Leitner-Dagan, Y., Krichevsky, A., Taylor, T., Vainstein, A., and Citovsky, V. 2005. pSAT vectors: A modular series of plasmids for auto-fluorescent protein tagging and expression of multiple genes in plants. Plant Mol. Biol. 57:503-516.

Uhrig, J. F., Canto, T., Marshall, D., and MacFarlane, S. A. 2004. Relocalization of nuclear ALY proteins to the cytoplasm by the tomato bushy stunt virus P19 pathogenicity protein. Plant Physiol. 135:2411-2423.

Vijaya Palani, P., Kasiviswanathan, V., Chen, J. C., Chen, W., Hsu, Y. H., and Lin, N. S. 2006. The arginine-rich motif of Bamboo mosaic virus satellite RNA-encoded P20 mediates self-interaction, intracellular targeting, and cell-to-cell movement. Mol. Plant-Microbe Interact. 19:758767.

Walhout, A. J., Temple, G. F., Brasch, M. A., Hartley, J. L., Lorson, M. A., van den Heuvel, S., and Vidal, M. 2000. GATEWAY recombinational cloning: Application to the cloning of large numbers of open reading frames or ORFeomes. Methods Enzymol. 328:575-592.

Walsh, D., and Mohr, I. 2006. Assembly of an active translation initiation factor complex by a viral protein. Genes Dev. 20:461-472.

Wang, Y., and Kumar, P. P. 2007. Characterization of two ethylene receptors PhERS1 and PhETR2 from petunia: PhETR2 regulates timing of anther dehiscence. J. Exp. Bot. 58:533-544.

Whitham, S. A., Yang, C., and Goodin, M. M. 2006. Global impact: Elucidating plant responses to viral infection. Mol. Plant-Microbe Interact. 19:1207-1215.

Wiemann, S., Arlt, D., Huber, W., Wellenreuther, R., Schleeger, S., Mehrle, A., Bechtel, S., Sauermann, M., Korf, U., Pepperkok, R., Sultmann, H. and Poustka, A. 2004. From ORFeome to biology: A functional genomics pipeline. Genome Res. 14:2136-2144.

Xiao, S., Charoenwattana, P., Holcombe, L., and Turner, J. G. 2003. The Arabidopsis genes RPW8.1 and RPW8.2 confer induced resistance to powdery mildew diseases in tobacco. Mol. Plant-Microbe Interact. 16:289-294.

Zhao, Q., Leung, S., Corbett, A.H., and Meier, I. 2006. Identification and characterization of the Arabidopsis orthologs of nuclear transport factor 2, the nuclear import factor of ran. Plant Physiol. 140:869-878.

Zuidema, D., Heaton, L. A., and Jackson, A. O. 1987. Structure of the nucleocapsid protein gene of Sonchus yellow net virus. Virology 159:373380 . 